\title{
Pre-service Teachers' Practices towards Digital Game Design for Technology Integration into Science Classrooms ${ }^{\text {i,ii }}$
}

\author{
Gulsah Uluay, ${ }^{1, *}$, Alev Dogan ${ }^{2}$ \\ ${ }^{1}$ Department of Science Education, Faculty of Education, Ahi Evran University, Turkey \\ ${ }^{2}$ Department of Science Education, Faculty of Gazi Education, Gazi University, Turkey
}

Copyright $\bigcirc 2016$ by authors, all rights reserved. Authors agree that this article remains permanently open access under the terms of the Creative Commons Attribution License 4.0 International License

\begin{abstract}
The main purpose of the study is to introduce Kodu Game Lab that is created by Microsoft as an example for technology integration into learning process to pre-service science teachers with MAGDAIRE framework. The participants were in a special teaching methods course at a university in Turkey during the fall 2015 semester. Mix method research design was used in the study. Technical Proficiency of Kodu Concepts Test (TPKC-T) and semi-structured interview form were used to collect data. To compare the participants, an experimental group who attended the course designed with MAGDAIRE framework $(n=18)$ and a control group who didn't study with MAGDAIRE framework $(\mathrm{n}=18)$ were organized. According to analysis results of data collected with TPKC-T, experimental group's post-test mean is significantly higher than control group's post-test mean. Based upon analysis of interview questions, it can be reported that PSTs in experimental group have more positive opinions towards Kodu and digital game based learning than PSTs' in control group.
\end{abstract}

Keywords Teacher Education, Technology Integration, Digital Game, Instructional Design

\section{Introduction}

In the second half of the 20th century, the explosion of personal computers and their potential with internet connection revolutionized forms of communication and have affected learning and teaching deeply [1]. Along with this effect and the rapid development of technology, computer-based tasks and other kinds of instructional technologies have entered the educational programs in recent years [2].

Use of technology for instructional purposes has potential to improve teaching and learning process [3]. The Center for
Applied Research in Educational Technology (CARET) has collected compelling research findings and has indicated that how technology affect student achievement and academic performance [4]. According to CARET, technology supports the development of higher-order thinking skills and critical thinking skills [4]. Teaching and learning environment can be made more interactive and the instructions more efficient by technology [2]. Technology also supplies copious resources for teaching and learning environment [3]. Besides, technology can improve students' motivation [5], [6], [7].

Of course, the use of technology alone does not motivate students [8]; because new generations are extremely conversant with new technologies [9] and they have lived in the midst of technology all their lives [8]. Thus, learning circumstances and methods that keep learners engaged must be created and integrating computer games into education is one approach that can be used for this purpose [8]. Although it is a very old and traditional approach, learning with computer games has just exploited fully and systematically [10].

Why should be computer games used in learning progress? Computer games present fun that is a part of the natural learning process in individual progress [11] and fun motivate students [12]. Computer games offer instant and visual feedbacks that also motivate learners [13]. Information that is presented by the computer games' worlds creates a riveting experience and continued interest [13]. By means of digital games, students can take control over their own learning processes [14]. It is suggested that digital games can be a useful tool in supporting learning [15]. In brief, computer games can stimulate pleasure, motivation and engagement of learners, helping recall and information retrieval, and encourage the development of various social and cognitive skills [12].

All over the world, teacher training agencies make an endeavor to reorganize their curriculums [73] since it is supposed to be designed these agencies' curriculums to train pre-service teachers who can use adequately technology for 
their own instructional practices in the age of digital world [74]. From this point of view, we wanted to design a lesson plan that consisted of usage of special software and creating an instructional activity by using the determined software. In this context, we designated firstly the software as Kodu Game Lab. Then, we organized our lesson plan based on MAGDAIRE framework.

The purpose of this study is to introduce Kodu Game Lab that is created by Microsoft as an example for technology integration into learning process to PSTs and make PSTs design their own digital game activities by developing their proficiency about Kodu. This study also attempts to investigate PSTs' views and perceptions of integrating technology into classroom. Based on these mentioned objectives, the research questions of the study were:

$\boldsymbol{R Q 1}$. Is it possible to improve PSTs' Kodu Game Lab proficiency in designing digital game activities by using MAGDAIRE framework for science teaching?

RQ2. What are PSTs' opinions toward intent to integrate digital game based learning into their classrooms?

RQ3. What are PSTs' views about using digital game activities in their future career?

\section{Literature Review}

\subsection{Digital Game Based Learning}

It has been highlighted that play is a principal socialization and learning mechanism particular to all human cultures [16]. According to [17], make-believe play ensure opportunities that are replicating real-life controversies, finding proper solutions for children's own pleasure, and amending negative feelings. Play and learning are in cooperation closely [18] and by means of this cooperation games can ensure an engaging environment for learning [8], because gaming is one of the natural ways for knowledge and skill acquiring [10]. According to [16], games embody cognitive disequilibrium and resolution that are parts of Piaget's theories about learning that involve the concepts of assimilation and accommodation [19].

Digital games are multimodal texts with a combination of diversified communicative media that can contain stationary and moving images, sound and music, and speech and writing [20]. Digital games that are interactive are designed for players to actively engage with games' systems and these systems react to players agentive behaviors [21]. Based upon sophisticated game design, users can create worlds, take risks, make decisions, navigate complex information streams, and determine and solve problems [20]. Games may impress learning in two ways in theory and first of the ways actualizes by changing the cognitive processes and the second actualizes by influencing the motivation [22]. Game theory indicated that computer games are extremely engaging, motivating, and interactive [23], and it supports that thanks to playing games, the brain work more efficiently [24].

Learning with fun seems to be more effective [25], because fun provides relieved percipient frame of mind for learning [12]. Due to increasing learner's participation that is arising from satisfaction been procured playing, it aids learner in learning [13] and [13] stated that fun and games are had to inject into training. Teaching with serious games is more effective than teaching with conventional instruction methods [22], because learning occurs in a meaningful and relevant context that is directly associated with game's environment and this principle is termed as situated cognition by researchers [16].

Many researchers pointed out various qualifications of digital games. In general, it can be said that digital games can be used to develop student engagement, disciplinary literacy, and content knowledge by trainers [20]. Digital games can motivate learners by inspiring relish [26], [20], [27], [28], [29], [12], [30], [31], [13], [32] and [15]. Due to gaining experience in the game world, digital games offer learning by doing opportunity [33]. Digital games also ensure tools to promote creative learning activity and experience design [34]. Digital games can enhance students' low levels of self-efficacy [35], and self-esteem [36]. Digital games promote a wide range of cognitive skills [21] and they necessitate players to master skills such as adaptation to change, strategic and analytical thinking, decision making [20]. Digital games can also improve problem solving skills [37], [38], [20] and [39]. In addition to all these, spatial thinking can be improved substantially by playing active games [40], [41] and [42] and according to [43], spatial thinking skill correlates with employment in engineering and science. Besides, due to emerging brain oscillations that is related to navigational and spatial learning more frequently in more complex games [12], users' learning and recollection talents remain and their academic, social and computer literacy abilities encourage [44].

\subsection{Framework of MAGDAIRE}

[45] developed a framework referred to MAGDAIRE that is scaled up [46]'s 4-phase cyclic. This framework that is abridged from modeled analysis, guided development, articulated implementation, and reflected evaluation transform pre-service science teachers' roles of passive users of technology into active designers of technology [45]. The aims of the MAGDAIRE framework are stated by the researchers as follows: "(1) to promote pre-service teachers' (PSTs') technology competency in order to customize technology-integrated materials for science instruction; (2) to construct an authentic context in which PSTs can reexamine the connection between the affordances of technology and their teaching practices." PSTs work collaboratively on creating practicable Online Science Coursewares (OSCs) and instructors and peers can develop OSCs [45]. The framework is demonstrated in Figure 1. 


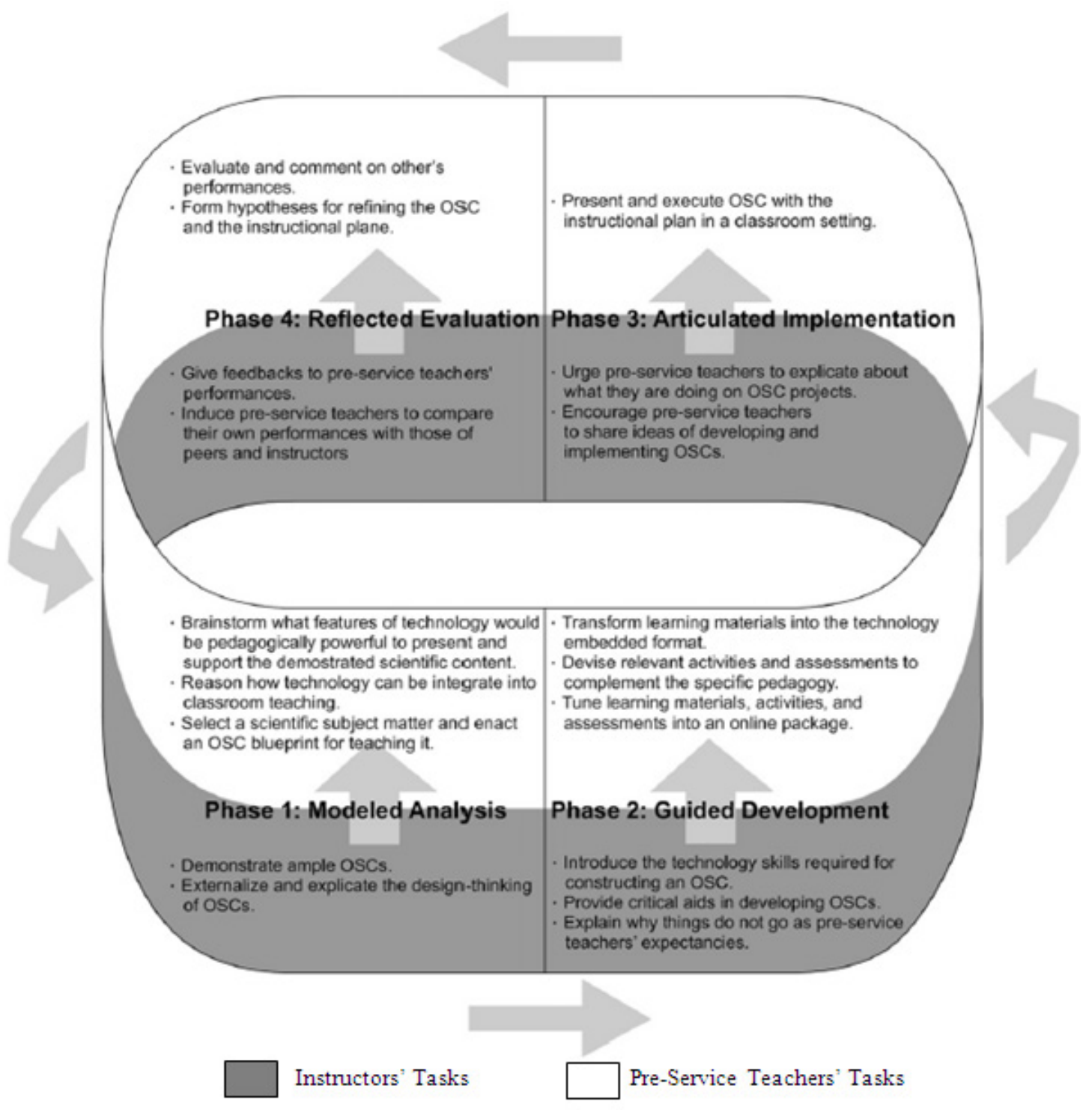

Figure 1. Framework of MAGDAIRE [45] Each phase of MAGDAIRE is explained as the follows [45]:

\subsubsection{Modeled Analysis}

Firstly, PSTs are divided into sub-groups and then instructors implement the plan that is as illustrated in Phase 1 of Figure 1. Within this period, PSTs brainstorm with instructors and group members as described in Phase 1 of Figure 1. Finally, each group of PSTs selects a scientific subject matter and designs their OSCs.

\subsubsection{Guided Development}

In this step, instructors demonstrate the technology skills that are necessary for generating an OSC to PSTs. Then each group performs implementations as illustrated in Phase 2 of Figure 1Instructors implement the steps that are as described in Phase 2 of Figure 1.

\subsubsection{Articulated Implementation}

In this step, all groups present and practice their OSCs by using instructional plans in a classroom setting. In the meantime, instructors encourage PSTs and implement the plan that is as illustrated in Phase 3 of Figure 1.

\subsubsection{Reflected Evaluation}

This phase is the formative assessment and triggers the next cycle of MAGDAIRE. In this step, PSTs assess and make interpretations on other groups' performances as illustrated in Phase 4 of Figure 1. By means of this process, PSTs take the opportunity to compare their own performances with peers' performances. Instructors implement the steps that are as described in Phase 4 of Figure 1. [45] offered suggestions for this evaluation as follow:

"In addition, pre-service teachers are engaged in collaboratively testing the hypotheses that they form on reflections for improving OSCs. The role-playing in the cognitive apprenticeship gradually shifts from the instructors between the pre-service teachers to the more skilled pre-service teachers between the less skilled preservice teachers. In order to refine OSCs to best fit their field practices, pre-service teachers have to 
iteratively deliberate and experiment on the manner in which the subject matter and teaching/learning processes might be shaped by the application of technology." (p. 581)

\section{3. Gaps}

Teachers mostly use technology for some kind of aims such as recording, forming lesson plans, and communications in the school and with parents; contrary to this common use of technology it is a rare situation to see teachers use technology to promote higher-order thinking, student-centered learning, or student enrichment [3]. In other words, unfortunately, teachers still use computers principally for administrative tasks rather than teaching [47]. One of the reasons for this situation is that computers require more effort by the teachers for perceived cognitive gain and it is researchers' job to find a way rather than teachers' blame [24]. Due to technology's importance in education that is summarized briefly in this paper, determining the potential barriers to the technology integration in schools would be a significant step in the quality of teaching and learning [48].

Teachers often lack for the skills and knowledge that are essential to integrate technology effectively into their instructions [47]. It is a critical situation, because teachers need to feel capable enough to use and integrate technology into their classrooms [2]. It is vital to prepare teachers to use technology efficaciously in the classroom [47], to help and support PSTs in obtaining technological special skill to enable better learning for present day's multifarious student population [49]. In Turkey, most of the teachers still abstain from integrating technology into their classrooms [50] and teachers frequently encounter problems about using technology during teaching process [51]. [52] pointed out that although there has been too much attempts about developing teachers' technological efficiencies over the past decade in Turkey, these attempts can't achieve the goals about providing information age's requirements. The main reason of these results is lack of undergraduate PST training [53]. Although teachers are interested in using games in their classrooms heavily, significant genuine barriers such as a lack of resources and a lack of understanding of how to use games to espousing were in sight [47]. According to [54], "If educators and other adults who are unfamiliar with games were able to learn about them in relation to their educational affordances, it might make using games in the classroom easier for educators, more effective for enhancing learning, and even more motivating for students." and secondary schools, colleges and universities have resisted digital games' use. These institutions presented courses on how to use and design games are very few [54], [47] and [55] highlighted that it is really important to support teachers before and after game play for providing effectiveness. Most of the reports about digital game based learning contain unfamiliar technology [47]. Starting from these points of view, the current study aims to introduce digital game based learning with Microsoft Kodu Game Lab to PSTs.

\section{Materials and Methods}

In this study, mix method research design compounded qualitative and quantitative methods, approaches and concepts in a single study [56] were used. According to [57], to compound qualitative and quantitative methods in a single research aids researchers in explaining various aspects of investigated subject by providing more integrative understanding. Within this context main purpose of mix method researches is to develop understanding relative to the subject [58].

\subsection{Procedures}

In Turkey, the higher education system is supervised by the Council of Higher Education (CoHE) and the CoHE is responsible for designing, coordination and governance of higher education system. According to CoHE's system, the senior students who are in department of science education complete major area courses such as general chemistry, and general physics; professional teaching knowledge courses such as educational psychology, teaching principles and methods, and instructional technologies and material design; and general culture courses such as scientific research methods, and computer lessons [59].

In this study, a science course subject of 7 th grade of secondary school that is termed "The Structure and Properties of Matter" was chosen to create lesson plan. We determined a specific content, because according to [60], it is seen that useful effects of digital game based learning can be observed when specific content and its objectives are defined. Mentioned course subject consists of six main topics as follows: (1) Elements and their symbols, (2) structure of atom, (3) phrase of electrons and chemical properties, (4) chemical bond, (5) compounds and their formulas, and (6) mixtures.

Microsoft Kodu Game Lab was used for game-design software in this study. Kodu is a visual programming that makes more specific creating a game [61]. Kodu is designed specifically for young children to learn through independent exploration [62]. Kodu has a simple language and entirely icon-based [61]. Kodu rules are regular expressions with a simple syntax [63]. The software is integrated in a 3D game environment and it presents more appealing visual for students [37]. In addition to these, Kodu for the PC is free to download. Due to Kodu's accessibility, easier to use and visual appeal, as mentioned previously, we choose this software, because teachers are in need of reaching resources quite easily [47].

\subsection{Participants}

The participants in this study were senior students in a teacher education program at a public university in Turkey. They were a total of 36 PSTs in a special teaching methods course during the fall 2015 semester. This course aims to make PSTs to prepare a lesson plan that includes materials about chosen course subject, present this lesson plan, and 
evaluate their performances related to professional teaching knowledge and skills. 18 participants of all are in experimental group and rest 18 participants are in control group.

\subsection{Experimental Group}

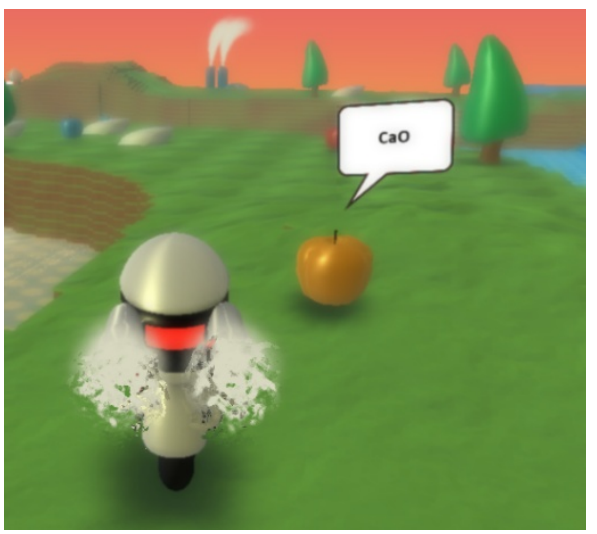

Figure 2. Road of compounds

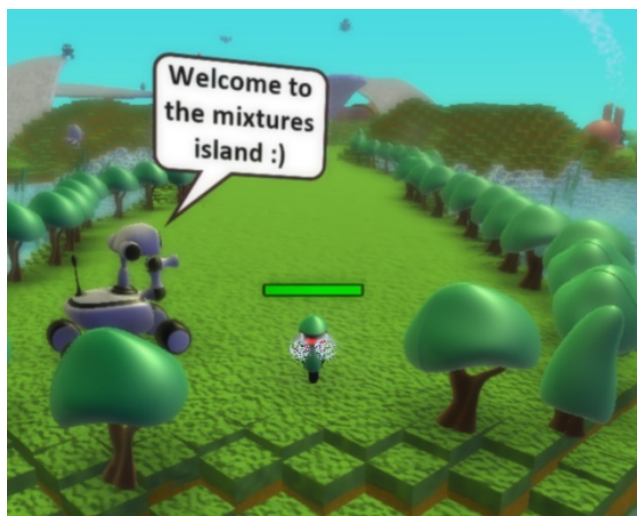

Figure 3. Mixtures Island

The present study's special teaching methods course plan was designed according to the course's aim as mentioned above with framework of MAGDAIRE. 18 of PSTs who participated in this course voluntarily formed six groups. This group's lesson plan is as illustrated in Table 1. Examples of digital games been designed by PSTs are shown in Figure 2 and Figure 3.

Table 1. Course content

\begin{tabular}{|c|c|c|}
\hline Phase & Week & Activity \\
\hline & $\begin{array}{l}1 \text { st }(2 \\
\text { hours })\end{array}$ & $\begin{array}{l}\text { Instructors present technological equipment and software that can be used integrating technology to the } \\
\text { classrooms. By the end of the presentation, PSTs are divided into sub-groups. }\end{array}$ \\
\hline $\begin{array}{l}\text { Modeled } \\
\text { Analysis }\end{array}$ & $\begin{array}{l}1 \text { st }(2 \\
\text { hours })\end{array}$ & $\begin{array}{l}\text { PSTs examine presented instructional plans that are designed for technology integration into learning process and } \\
\text { they brainstorm about these plans and their availability. Instructors direct this process and encourage PSTs to state } \\
\text { clearly their own ideas. By the end of the brainstorming activity, instructors introduce PSTs about a science course } \\
\text { subject of 7th grade that is termed "The Structure and Properties of Matter". This course subject has five } \\
\text { subtopics. Every group chooses a subtopic by lot and all groups start to prepare an instructional plan that bases on } \\
\text { digital game design and learning. }\end{array}$ \\
\hline \multirow{4}{*}{$\begin{array}{c}\text { Guided } \\
\text { Development }\end{array}$} & $\begin{array}{l}2 \text { nd }(2 \\
\text { hours })\end{array}$ & $\begin{array}{l}\text { A software that can be used in science education is introduced and technical characteristics about use of software: } \\
\text { - } \quad \text { Kodu Game Lab: Introduction about encountered first windows when software is started } \\
\text { - } \quad \text { Kodu Game Lab: General overview about tools and objectives of their use } \\
\text { - } \quad \text { Kodu Game Lab: Painting, adding, or deleting ground } \\
\text { - } \quad \text { Kodu Game Lab: Adding or editing characters or objects (for example; change of color, change of size) }\end{array}$ \\
\hline & $\begin{array}{l}2 \text { nd }(2 \\
\text { hours })\end{array}$ & $\begin{array}{ll}\text { - } & \text { Kodu Game Lab: Programming } \\
\text { - } & \text { Kodu Game Lab: Adding or editing paths } \\
\text { - } & \text { Kodu Game Lab: Adding, removing, or tinting water } \\
\text { - } & \text { Kodu Game Lab: Creating a new world for an example } \\
\end{array}$ \\
\hline & $\begin{array}{l}3 \text { rd }(2 \\
\text { hours })\end{array}$ & $\begin{array}{l}\text { - Kodu Game Lab: Scoring and winning the game } \\
\text { - } \quad \text { Kodu Game Lab: Adding a countdown or enumerative timer } \\
\text { - } \quad \text { Kodu Game Lab: Introduction about world settings tabs and objectives of their use } \\
\text { Each one of all these phases, when instructors get showing an application over, PSTs perform the same } \\
\text { application with their own laptops. All groups started to create their own digital games that are associated with } \\
\text { their course subject. }\end{array}$ \\
\hline & $\begin{array}{l}3 \text { rd }(2 \\
\text { hours })\end{array}$ & $\begin{array}{l}\text { PSTs create activities that are associated with their course subject by studying in groups and they evaluate their } \\
\text { own activities. }\end{array}$ \\
\hline \multirow{2}{*}{$\begin{array}{l}\text { Articulated } \\
\text { Implementation } \\
\text { \& Reflected } \\
\text { Evaluation }\end{array}$} & $\begin{array}{l}\text { 4th }(2 \\
\text { hours })\end{array}$ & $\begin{array}{l}\text { Every group introduces instructional plans that base on DGBL and practices. Instructors give feedback that is } \\
\text { related to groups' performance and their activities. Instructors ask PSTs to evaluate the other groups' performance } \\
\text { and express their opinions. }\end{array}$ \\
\hline & $\begin{array}{l}4 \text { th }(2 \\
\text { hours })\end{array}$ & $\begin{array}{l}\text { Every group introduces instructional plans that base on DGBL and practices. Instructors give feedback that is } \\
\text { related to groups' performance and their activities. Instructors ask PSTs to evaluate the other groups' } \\
\text { performances and express their opinions. }\end{array}$ \\
\hline $\begin{array}{l}\text { Modeled } \\
\text { Analysis }\end{array}$ & $\begin{array}{l}5 \text { th }(2 \\
\text { hours })\end{array}$ & Instructors introduce solution offers about diverse problems observed from each group's presentation. \\
\hline $\begin{array}{c}\text { Articulated } \\
\text { Implementation }\end{array}$ & $\begin{array}{l}\text { 6th }(2 \\
\text { hours })\end{array}$ & PSTs introduce instructional plans based on DGBL and explain their digital games. \\
\hline $\begin{array}{l}\text { Reflected } \\
\text { Evaluation }\end{array}$ & $\begin{array}{l}6 \text { th }(2 \\
\text { hours })\end{array}$ & out these performances. \\
\hline
\end{tabular}


The groups choose their own subjects to create digital games as the follows:

Table 2. Course Subject Matter for Each Group

\begin{tabular}{|c|c|}
\hline Groups & Activity Subject \\
\hline Group 1 (PST1, PST2, PST3) & Elements and Their Symbols \\
\hline Group 2 (PST4, PST5, PST6) & Structure of Atom \\
\hline Group 3 (PST7, PST8, PST9) & $\begin{array}{c}\text { Phrase of Electrons and Chemical } \\
\text { Properties }\end{array}$ \\
\hline Group 4 (PST10, PST11, PST12) & Chemical Bond \\
\hline Group 5 (PST13, PST14, PST15) & Compounds and Their Formulas \\
\hline Group 6 (PST16, PST17, PST18) & Mixtures \\
\hline
\end{tabular}

\subsection{Control Group}

PSTs who were in the control group were in the same special teaching methods course with PSTs been experimental group. MAGDAIRE framework wasn't used in this group's lessons. Researcher presented technological equipment and software that can be used integrating technology to the classrooms as with the experimental group. After this presentation, Kodu was started to introduce and this process was supported by Microsoft PowerPoint presentations. It wasn't asked PSTs to create a special activity about Kodu.

\subsection{Data Collection}

\subsubsection{Technical Proficiency of Kodu Concepts Test}

Technical Proficiency of Kodu Concepts Test (TPKC-T) that contains 36 true-false items is developed according to the tech-notes from the Kodu Game Lab Resources [61]. The purpose of TPKC-T is to measure quantitatively PSTs' skills been essential to use Kodu. The tech-notes give directions about Kodu's general features and its running. Because of the tech-notes were in English, firstly they were translated into Turkish by two experts. Acquired two translations were evaluated by the researcher and two experts whose specialties are computer and instructional technologies and in accordance with suggestions, Turkish form was organized. Coordinated form was examined by two experts whose specialties are Turkish philology and in the light of their suggestions, form was made final shape. After finishing the translation process, think aloud protocols developed by [64] were implemented. According to [65], think aloud protocols are better than the other ways of collecting verbal data. These researchers suggested five steps that are points to consider while collecting data with think aloud protocols. In this study, the five steps were taken in consideration during think aloud protocols process that performed with five PSTs. Their permissions for recording were received. Every session was approximately 40 minutes. After finishing the sessions, the voice recordings were turned into texts and investigated deeply. By considering PSTs' comments such as "not clear", "complicated", form's final regulation was made and TPKC-T consisted of 36 items acquired.

As mentioned above, expert opinions were taken with an assessment form as 5-point Likert type for content validity of TPKC-T and think aloud protocols were performed for construct validity of TPKC-T. Reliability studies of TPKC-T were performed with 368 PSTs (202 female, 166 male) who study department of Computer and Instructional Technologies. All of PSTs are seniors with an age average of 22.2, ranging from 22 to 23. After examining the data, reliability studies were performed. At the analysis stage, IBM SPSS Statistics 20.0 software was used. Firstly, total scores of each item's correlations with total score of TPKC-T were tested. For this purpose, the $27 \%$ of who had the highest scores $\left(\mathrm{n}_{1}=99\right)$ were labeled as higher group and the $27 \%$ of who had the lowest scores $\left(n_{2}=99\right)$ were labeled as lower group. The significance of differences between higher and lower groups for each item was tested with independent samples t-test. After this step, item means, standard deviation, and coefficient of Pearson correlation (item-scale correlation) were calculated. Analysis results are demonstrated in Table 3. According to total item correlations, items numbered $3,4,5,8,17$, and 21 were removed from TPKC-T. Thus, total item correlations were ranging from .503 to .815 and the items been .50 and above are acceptable [66]. From this point of analysis results, it can be said that these 30 items are consonant with KPTY-T. Cronbach's alpha firstly was found as .914 and when 6 items were removed from TPKC-T, Cronbach's alpha was calculated as .947 . 
Table 3. Results of reliability analysis

\begin{tabular}{|c|c|c|c|c|c|}
\hline Number of Item & Mean & $\mathrm{Sd}$ & t-test & $\mathrm{p}$ & Total Item Correlations (r) \\
\hline 1 & .6919 & .46287 & $9.962^{*}$ & .000 & $.584^{* *}$ \\
\hline 2 & .6515 & .47770 & $8.509^{*}$ & .000 & $.508^{* *}$ \\
\hline 3 & .6111 & .48873 & $7.805^{*}$ & .000 & $.496^{* *}$ \\
\hline 4 & .6616 & .47436 & $7.233^{*}$ & .000 & $.473^{* *}$ \\
\hline 5 & .5606 & .49757 & $6.427^{*}$ & .000 & $.428^{* *}$ \\
\hline 6 & .5152 & .50104 & $8.647^{*}$ & .000 & $.534^{* *}$ \\
\hline 7 & .5657 & .49693 & $8.746^{*}$ & .000 & $.530^{* *}$ \\
\hline 8 & .5960 & .49195 & $4.883^{*}$ & .000 & $.334^{* *}$ \\
\hline 9 & .5758 & .49548 & $13.528^{*}$ & .000 & $.694^{* *}$ \\
\hline 10 & .4848 & .50104 & $13.243^{*}$ & .000 & $.687^{* *}$ \\
\hline 11 & .5000 & .50127 & $18.537^{*}$ & .000 & $.789^{* *}$ \\
\hline 12 & .4899 & .50117 & $12.191^{*}$ & .000 & $.661^{* *}$ \\
\hline 13 & .6818 & .46695 & $7.826^{*}$ & .000 & $.503^{* *}$ \\
\hline 14 & .5758 & .49548 & $11.465^{*}$ & .000 & $.629^{* *}$ \\
\hline 15 & .5354 & .50001 & $10.160^{*}$ & .000 & $.618^{* *}$ \\
\hline 16 & .5101 & .50117 & $10.393^{*}$ & .000 & $.601^{* *}$ \\
\hline 17 & .2727 & .44649 & 1.275 & .204 & .102 \\
\hline 18 & .5354 & .50001 & $10.710^{*}$ & .000 & $.605^{* *}$ \\
\hline 19 & .5404 & ,49963 & $9.399^{*}$ & .000 & $.557^{* *}$ \\
\hline 20 & .4949 & .50124 & $10.668^{*}$ & .000 & $.604^{* *}$ \\
\hline 21 & .5051 & .50124 & $7.347^{*}$ & .000 & $.470^{* *}$ \\
\hline 22 & .5404 & .49963 & $11.010^{*}$ & .000 & $.623^{* *}$ \\
\hline 23 & .5202 & .50086 & $12.889^{*}$ & .000 & $.685^{* *}$ \\
\hline 24 & .4596 & .49963 & $14.505^{*}$ & .000 & $.725^{* *}$ \\
\hline 25 & .4747 & .50063 & $9.621^{*}$ & .000 & $.569^{* *}$ \\
\hline 26 & .5354 & .50001 & $19.345^{*}$ & .000 & $.815^{* *}$ \\
\hline 27 & .5000 & .50127 & $11.549^{*}$ & .000 & $.639^{* *}$ \\
\hline 28 & .5000 & .50127 & $8.874^{*}$ & .000 & $.550^{* *}$ \\
\hline 29 & .5758 & .49548 & $12.789^{*}$ & .000 & $.675^{* *}$ \\
\hline 30 & .6010 & .49093 & $11.331^{*}$ & .000 & $.643^{* *}$ \\
\hline 31 & .4798 & .50086 & $10.967^{*}$ & .000 & $.619^{* *}$ \\
\hline 32 & .5101 & .50117 & $10.956^{*}$ & .000 & $.616^{* *}$ \\
\hline 33 & .4899 & .50117 & $10.956^{*}$ & .000 & $.628^{* *}$ \\
\hline 34 & .4899 & .50117 & $9.862^{*}$ & .000 & $.590^{* *}$ \\
\hline 35 & .5303 & .50035 & $14.462^{*}$ & .000 & $.725^{* *}$ \\
\hline 36 & .4848 & .50104 & $12.532^{*}$ & .000 & $.677^{* *}$ \\
\hline
\end{tabular}

\subsubsection{Interview}

In this study, semi-structured interview was used to collect qualitative data, because semi-structured interview offers adequate flexibleness to consult with different respondents differently while still including the same areas of data collection [67]. Interview questions were carefully designed according to the purpose of the research to provide adequate reporting. After taking three experts' suggestions, the interview form was drafted. The form contains 5 open-ended questions. Based on the interviews' process, follow-up questions were in case of need asked to lead PSTs to give details about their answers. The interviews were conducted with 12 of PSTs who were selected randomly and by the same researcher. 6 of participants were selected from experimental group and each of them represented one of the groups that were mentioned above. 6 of participants were selected from control group. Selected participants are showed as follows:

Table 4. Distribution of participants

\begin{tabular}{|c|c|}
\hline Experimental Group & Control Group \\
\hline PST 2, PST 5, PST 9, PST 12, PST 13, PST 18 & PST 22, PST 24, PST 27, PST 28, PST 30, PST 33 \\
\hline
\end{tabular}

Participants' permissions were obtained for recording. Every recording was numbered and turned into texts. At the analysis stage, content analysis method was used and by means of the participants' same replies, categories, themes and codes were stated for each question. 
Table 5. Interview Guide

\begin{tabular}{|c|c|c|}
\hline Section & Instructions & Duration \\
\hline Introduction & $\begin{array}{c}\text { Purpose of the interview } \\
\text { Explanation about confidentiality of the interview } \\
\text { Asking permission for recording }\end{array}$ & $5-6 \min$ \\
\hline Demographic Data & Age, gender, purposes towards technology usage & $4-5 \mathrm{~min}$ \\
\hline $\begin{array}{l}\text { Interview } \\
\text { Questions }\end{array}$ & $\begin{array}{l}\text { 1. Can you explore the materials and tools that can be used for technology integration into the learning } \\
\text { process, thinking the materials and tools used/introduced by your instructors, please? } \\
\text { 2. Have you ever used digital game design software? If you used, please explain the software. } \\
\text { 3. Please describe the advantages and disadvantages that are provided by digital game based learning, } \\
\text { giving concrete examples. } \\
\text { 4. Please describe what you think about availability and usage of Kodu that was used for your lesson plan } \\
\text { by you. }\end{array}$ & $30-35 \mathrm{~min}$ \\
\hline
\end{tabular}

\section{Findings and Results}

\subsection{TPKC-T}

In this study, IBM SPSS Statistics 20.0 software was used for quantitative data analysis. Whether or not the data had normal distribution was firstly investigated. For this purpose, test of Shapiro-Wilks was used to analysis of pre and post-tests means because sample size was less than 50 [68]. Pre and post-test means were analyzed for both of the groups and it was seen that the data had normal distribution. Since the data had normal distribution and the groups that will be compared were unrelated, independent samples t-test method was used for analysis of TPKC-T. Analysis results of t-test are illustrated in Table 6 and Table 7. The effect sizes for $\mathrm{t}$-test were determined and interpreted as [69] stated (Cohen's d). Cohen's $d$ is interpreted in the manner of following characterization: $\mathrm{d}=.20$ is described as a small effect size, $\mathrm{d}=.50$ a medium effect size and $\mathrm{d}=.80$ a large effect size [69].

Table 6. Comparisons of pre-test means

\begin{tabular}{|c|c|c|c|c|c|c|}
\hline Group & $\mathrm{N}$ & $\bar{X}$ & $\mathrm{~S}$ & $\mathrm{Sd}$ & $\mathrm{t}$ & $\mathrm{p}$ \\
\hline $\begin{array}{c}\text { Experimental } \\
\text { group's pre-test } \\
\text { mean }\end{array}$ & 18 & 17.77 & 1.51 & 34 & 1.91 & $.065^{*}$ \\
\hline $\begin{array}{c}\text { Control group's } \\
\text { pre-test mean }\end{array}$ & 18 & 16.94 & 1.05 & & \\
\hline $\mathrm{p}>.01$
\end{tabular}

According to analysis results of pre-test scores, mean of PSTs in the experimental group ( $\bar{X}=17.77$ ) is higher than mean of PSTs in the control group $(\bar{X}=16.94)$, but there isn't statistically significant difference between means of experimental and control group $\left(\mathrm{t}_{(34)}=1,91, \mathrm{p}>.01\right)$. Effect size of this analysis was calculated as $\mathrm{d}=0.63$ and this value is interpreted as medium effect size.

The results of independent samples t-test analysis deduce that experimental group's post-test mean $(\bar{X}=23.05)$ is higher than control group's post-test mean $(\bar{X}=18.11)$ and there is statistically significant difference between experimental and control groups' post-test mean $\left(\mathrm{t}_{(34)}=3.94\right.$, $\mathrm{p}<.01)$. Effect size for post-test analysis was calculated as $\mathrm{d}=1.31$ that is evaluated as large effect size.

Table 7. Comparisons of post-test means

\begin{tabular}{|c|c|c|c|c|c|c|}
\hline Group & $\mathrm{N}$ & $\bar{X}$ & $\mathrm{~S}$ & $\mathrm{Sd}$ & $\mathrm{t}$ & $\mathrm{p}$ \\
\hline $\begin{array}{c}\text { Experimental } \\
\text { group's post-test } \\
\text { mean }\end{array}$ & 18 & 23.05 & 2.91 & 34 & 3.94 & $.000^{*}$ \\
\hline $\begin{array}{c}\text { Control group's } \\
\text { post-test mean }\end{array}$ & 18 & 18.11 & 4.44 & & \\
\hline
\end{tabular}

* $\mathrm{p}<.01$

In light of these findings, we can evaluate RQ1. When pre-test means of experimental and control group are compared with each other, statistically significant difference between groups isn't seen. Accordingly we can say that our groups equal with each other and thus comparisons of these groups' post-test means will inform about whether MAGDAIRE can develop PSTs' Kodu Game Lab proficiency or not. As illustrated in Table 7, post-test mean of experimental group is significantly higher than post-test mean of control group. Based on these findings, we can determine that it is possible to improve PSTs' Kodu Game Lab proficiency in designing digital game activities by using MAGDAIRE framework for science teaching.

\subsection{Interviews}

Question 1: Can you explore the materials and tools that can be used for technology integration into the learning process, thinking the materials and tools used/introduced by your instructors, please?

Our participants' answers to this question can be seen in Table 8 . When Table 8 is examined, it can be said that both groups' answers are similar with one another. They mostly mentioned general use of technology and didn't talk about newer strategies such as blogs, digital narration, digital games and newer software such as Ms Photostory Program, Kodu. 
Table 8. PSTs' opinions about technological tools and materials

\begin{tabular}{|c|c|c|c|c|}
\hline \multirow{2}{*}{ Themes and Codes } & \multicolumn{2}{|c|}{ Control Group } & \multicolumn{2}{c|}{ Experimental Group } \\
\cline { 2 - 5 } & Frequency & $\%$ & Frequency & $\%$ \\
\hline Technological tools & & & & \\
Computer & 6 & 100 & 6 & 100 \\
Tablet & 6 & 100 & 5 & 83 \\
Projector & 5 & 83 & 4 & 67 \\
Smart board & 4 & 67 & 5 & 83 \\
Overhead projector & 2 & 33 & 3 & 50 \\
Television & 2 & 33 & - & - \\
\hline Technological materials & & & & \\
Presentation & 6 & 100 & 6 & 100 \\
Animation & 5 & 83 & 4 & 67 \\
Video & 5 & 83 & 5 & 83 \\
Image & 4 & 67 & 3 & 50 \\
Sound & 3 & 50 & 1 & 17 \\
Movie & 2 & 33 & 2 & 33 \\
\hline
\end{tabular}

Our participants told us about conventional techniques mostly. All participants from both control group and experimental group remarked that they can use computers and presentations. For instance, PST 28's answer is presented below:

“... Computers and projectors can be used as tools. We can also use smart board... The first thing that comes to my mind is PowerPoint presentations as material. Our instructors mostly use presentations and they sometimes get us to watch short-time videos. I'm thinking now what I can do with computers, but to be honest I don't know another example for using computers or technology in the classroom. I have never used and seen other than these..."
Three participants from control group and four participants from experimental group stated that they don't have experiences towards integrating technology into the classroom. They also emphasized that they weren't provided guidance about ways of technology use. For example, PST 13 's answer is as follows:

“...I feel incompetent about using technology. I can use smart board and I can show images. I am sure that I will use PowerPoint. Movies such as science fiction or biography movies may be used. Since we haven't worked on technological activities or materials in our lectures, I can't exemplify more. Our instructors don't lead us to use technology and most of them don't use technology in the classroom."

Question 2: Have you ever used digital game design software? If you used, please explain the software.

PSTs in either groups stated that they had never used digital game design software. Only one of PSTs named as PST 30 said a software name different from Kodu as an example by stating that he didn't know how it is used. None of our participants told us about Kodu. When we asked about whether they are aware of Kodu or not, they stated that they didn't hear of Kodu. As an example, answer of PST 5 as follows:

"... I have never known about any software such as Kodu that is used for designing games. Thanks to this course, I am acquainted with this software..."

Table 9. PSTs' opinions about advantages of digital game based learning

\begin{tabular}{|c|c|c|c|c|}
\hline \multirow{2}{*}{ Themes and Codes } & \multicolumn{2}{|c|}{ Control Group } & \multicolumn{2}{|c|}{ Experimental Group } \\
\hline & Frequency & $\%$ & Frequency & $\%$ \\
\hline Personal Development & & & & \\
\hline Development of imagination & 3 & 50 & 5 & 83 \\
\hline Development of proficiency in the use of computer & 2 & 33 & 4 & 67 \\
\hline Development of social relations & 2 & 33 & 4 & 67 \\
\hline Development of mental process skills & - & - & 2 & 33 \\
\hline Classroom Environment & & & & \\
\hline Collaborative work & 2 & 33 & 4 & 67 \\
\hline Positive competition & - & - & 3 & 50 \\
\hline Brainstorming & 1 & 17 & 2 & 33 \\
\hline Interest & & & & \\
\hline Development of positive perspectives towards course & 3 & 50 & 6 & 100 \\
\hline Development of positive perspectives towards sciences & 2 & 33 & 5 & 83 \\
\hline Development of positive perspectives towards teacher & 2 & 33 & 3 & 50 \\
\hline Learning & & & & \\
\hline Learning with fun & 3 & 50 & 6 & 100 \\
\hline Effective learning & 2 & 33 & 5 & 83 \\
\hline Permanent learning & 1 & 17 & 4 & 67 \\
\hline Easy learning & - & - & 4 & 67 \\
\hline Create promotive activities & & & & \\
\hline Creating funny activities & 4 & 67 & 6 & 100 \\
\hline Creating activities developed imagination & 1 & 17 & 5 & 83 \\
\hline Creating interesting activities & - & - & 3 & 50 \\
\hline Attendance to lesson & & & & \\
\hline Active attendance & 2 & 33 & 6 & 100 \\
\hline Willing attendance & 2 & 33 & 6 & 100 \\
\hline Voluntary attendance & 1 & 17 & 4 & 67 \\
\hline
\end{tabular}


Question 3: Please describe the advantages and disadvantages that are provided by digital game based learning, giving concrete examples.

Categories that were determined for this question were divided into two parts as "advantages of Kodu" and "disadvantages of Kodu" as illustrated in Table 9 and Table 10. There are six themes in the part of advantages of Kodu termed as "personal development", "classroom environment", "interest", "learning", "create promotive activities" and "attendance to lesson". Two themes termed as "software" and "lesson plan" were created for the part of disadvantages of Kodu.

PSTs evaluated the advantages of digital game based learning by thinking digital games' possible impacts on middle school students. They particularly determined that it is the age of technology and middle school students spend most of their time by surfing the internet or playing computer games. Five participants from the experimental group stated that this circumstance arising from students' technology addiction can be capitalized on courses and course of proceeding can be more productive in the classroom with digital game based learning. These participants emphasized that learning with fun will be easier and more interesting for students. Statement of PST 18 is cited as follows:

“...Today's world live with technology and nearly all of us addict technological tools such as computers. Especially children are on the computer during most part of the day. In the present case, they can learn while they are using their computers... Digital games are based upon fictions, and thus they develop both imagination and mental process skills. The students who we are going to teach will have a great imagination due to their ages. Thanks to these digital games, they can think limitlessly and brainstorm easily. They will learn to write script applied to characters that were created with their own imagination and love learning mostly."

Four participants from the control group determined that digital game based learning can create a funny environment in the classroom, but only two of them indicated that it might provide students with opportunity about learning. When values of $f$ and $\%$ in Table 9 are investigated, it is seen that participants of experimental group have more positive opinions than participants of control group. For example, theme named "entertainingly learn" is $\% 83$ for experimental group while this value is $\% 33$ for control group.

Three participants from the control group determined that middle school-age children play computer games too much, but they are unsettled about how can be integrated this situation into the classroom or whether these games can be integrated into the courses or not. PST 24 and PST 33 stated that children have already spent time on playing computer games overmuch and in the present case playing game in the classroom is not in keeping with for the course. They determined that teaching with digital games couldn't provide any benefits. They also thought that it is not possible to teach subjects to students, so Kodu has no advantages according to them. As seen in Table 10, two themes were created for disadvantages of Kodu.

Table 10. PSTs' opinions about disadvantages of digital game based learning

\begin{tabular}{|c|c|c|c|c|}
\hline \multirow{2}{*}{ Themes and Codes } & \multicolumn{2}{|c|}{ Control Group } & \multicolumn{2}{c|}{$\begin{array}{c}\text { Experimental } \\
\text { Group }\end{array}$} \\
\cline { 2 - 5 } & Frequency & $\%$ & Frequency & $\%$ \\
\hline $\begin{array}{c}\text { Software } \\
\text { Limitation of software }\end{array}$ & 4 & 67 & 2 & 33 \\
Not possible to modify & 2 & 33 & 2 & 33 \\
software & & & & \\
\hline Lesson Plan & 5 & 83 & 1 & 17 \\
Lack of course time & 3 & 50 & - & - \\
\hline
\end{tabular}

While PSTs were forming estimates of disadvantages of digital game based learning, they mainly thought about potential problems encountered in the classroom. They tried to explain problems that can arise out of the software. Since they don't know any software except for Kodu, they commented software problems based on Kodu and we constituted "software" theme. Falling into this category themes related to Kodu's unconvertible features about limited characters and actions. For example, PST 12 expressed this problem as follows:

"There aren't sufficient numbers of characters in Kodu. I wish Kodu had more characters. We also couldn't realize our project that was designed for lesson plan since movements of characters were inadequate. For this reason, we had to change our scenario."

The other potential problems are related to teacher and weekly course hours. Our participants pointed out that process of preparing scenarios and digital games will be too much for teachers. They also reported that course hours will fall short for both achieving instructional objectives and using Kodu. They stated that they have doubts about whether complete the course subject or not. Answer of PST 28 as cited:

"In my opinion, disadvantages will impress the teacher, because teacher has to make ready for course and this work will be time-consuming and really onerous. I also have to think course time as a teacher... Course time that is specified according to curriculum isn't sufficient to use digital game software such as Kodu. I should teach both course subject and usage of Kodu. I don't think that my time will be adequate for all these."

PST 2, PST 9 and PST 13 determined that there aren't any disadvantages of Kodu. They determined that since Kodu has easier to use, children will learn it easily. According to them, Kodu will increase their motivations, because they will be playing computer games even if they are in the classroom.

When values of $f$ and $\%$ in Table 10 are investigated, it is seen that participants of control group have more negative 
opinions than participants of experimental group. For example, the code named "lack of time" is $\% 83$ for control group while this value is $\% 17$ for experimental group. Also, there are three participants from control group in the code of "preparation of teacher", on the contrary no one from experimental group mentioned this problem to us.

Question 4: Please describe what you think about availability and usage of Kodu that was used for your lesson plan by you.

While our participants were answering question 3, they generally dwelled on software installation, functioning for creating digital games with the software and usage of Kodu activities. For this question, we formed two categories and termed as "negative opinions about Kodu" and "positive opinions about Kodu”. Two participants from control group, PST 24 and PST 33, had only negative opinions about availability and usage of Kodu. According to them, Kodu is not useful for science education and science teachers since to use Kodu is difficult. They stated that Kodu can be useful for computer lessons and these lessons' teachers. For example, PST 33's answer is cited:

"Usage of Kodu is really hard. In other words, it is too hard for me... I had difficulty in designing worlds and coding characters. I have never used software such as Kodu and I heard digital game based learning for the first time. I'm not sure that many in-service teachers and PSTs from different universities know Kodu or digital game based learning. Consequently, to access and use software such as Kodu requires in-depth research and this is not an easy work."

For category of "positive opinions about Kodu", two themes that were entitled "availability of Kodu" and "usage of Kodu” were found as illustrated in Table 11.
PST 5', PST 18's and PST 22's answers are respectively cited as follows:

"It is quite easy to find online Kodu. Since coding with this software is an easy task, using Kodu won't be difficult for students. It is really perfect that such practical software is free. I had really fun while I was designing digital games. I want to indicate that we can both fun and develop our imagination by designing with Kodu."

"Use of Kodu game lab is really easy and it is also simple to find the software online. Even little children can download and set up the software. In addition to all these, there are lots of videos that are published on the internet demonstrate us the way to use Kodu. Anyone can learn use of Kodu by watching the videos and create a world like his dreams. We can also share our own worlds on the internet and by this means we can find lots of instances. It helps us to develop our worlds and our imagination."

“... It is very important that we can adjust difficulty level of games with Kodu. On this feature's coattails we can develop games correspondent with our students' ability of playing digital games. In short, a student who can't play computer games well won't lose motivation or a student who is good at digital games won't get bored, because I can design simple and difficult games for each."

As is seen from Table 11, all PSTs from experimental group explained that Kodu is user-friendly software since it has simple coding. Three participants from control group held opinion with experimental group. According to Table 11, PSTs from experimental group have more positive opinions about availability and usage of Kodu than PSTs from control group.

Table 11. PSTs' opinions about availability and usage of Kodu

\begin{tabular}{|c|c|c|c|c|}
\hline \multirow{2}{*}{ Themes and Codes } & \multicolumn{2}{|c|}{ Control Group } & \multicolumn{2}{|c|}{ Experimental Group } \\
\hline & Frequency & $\%$ & Frequency & $\%$ \\
\hline Availability of Kodu & & & & \\
\hline Ease of finding online & 3 & 50 & 5 & 83 \\
\hline Ease of free software & 3 & 50 & 5 & 83 \\
\hline Ease of installation & 2 & 33 & 6 & 100 \\
\hline Ease of finding variety of world instances & - & - & 3 & 50 \\
\hline Usage of Kodu & & & & \\
\hline Ease of coding & 3 & 50 & 6 & 100 \\
\hline Ease of creating world & 2 & 33 & 5 & 83 \\
\hline Ease of adding characters & 2 & 33 & 6 & 100 \\
\hline Ease of adjusting game's difficulty & 1 & 17 & 4 & 67 \\
\hline
\end{tabular}




\section{Question 5: Please describe what you think about using} digital game based learning in your future career.

Categories that were determined for this question were divided into two parts as "negative future plans towards digital games" and "positive future plans towards digital games". Three participants from control group, PST 24, PST 27 and PST 33, determined that they won't use digital games in their own classrooms since designing digital games is difficult and effortful. PST 27 is also stated that while students are playing digital games, supervision and classroom management will be harder. For example, PST 27 's answer is cited as follows:

"I don't think that middle school students can't use this software easily. While even university students can't use the software properly, the students' age-group levels aren't poised of digital game based learning. I also think that classroom management will be very tough during playing digital games since checking in on students will become more difficult... Due to these reasons, I don't think about using digital games in my future career."

According to PST 24, computer games are just for fun and they can't be used for learning process:

"While I was talking about advantages of Kodu, I told that we can create funny activities. I don't think that I can teach science with fun since science is an important and critical course. I love playing computer games so much, but games are not for courses. Trying to teach science with digital games is only waste of time..."

All participants from experimental group and three participants from control group indicated their positive opinions about using digital game based learning in their future careers. While they were accounting for their opinions' reasons, they touched on digital games' positive effects on learning process. As examples, answers of PST 2 and PST 12 as follows:

"Kodu brought down my prejudices towards digital game design. As I get to play and become familiar with Kodu, I realized that I took a liking to it. Every teacher can dramatize the courses in the classroom and by this means learning process will be easier and more fun. I will absolutely use Kodu and digital game based learning in my future class..."

"I think that digital game design should be used in the classrooms since by using digital game based learning students will learn course subjects effectively and permanently... Especially teachers should use digital game based learning while they are teaching course subjects been abstruse and boring for students. In this way, they can lead their students to learn entertainingly and also active attendance to lesson can be provided... In short, I really like this method and I will use it."
PSTs in experimental group also stated that group working is effective for them since they get the chance to collaborate and exchange opinions with group members. All of them underlined importance of intergroup evaluations. According to PSTs, suggestions and complaints been made by the other groups on designed digital games were beneficial since they took the opportunity to know their own games' deficiencies and outperform the games. Due to their experiences, they are willing for their future students to join group workings including digital game activities. PST 9's answer as follows:

"Working with group friends is both funny and advantageous... We aid each other in creating the digital game and brainstorm. While other groups were talking about our game, we got advices for doing one better game and this process made us more imaginative. I really want to lead my future students to live the experiences of designing digital game such as mine."

It can be said that PSTs from experimental group tend to use digital games in their own future classrooms more than PSTs from control group. It can be reported that PSTs been at the experimental group mostly want to use digital games in their classrooms because of their opinions towards digital games' advantages. For example, all of PSTs from experimental group emphasized that if they use digital game based learning in the classroom, their students' perspectives towards course develop positively. This opinion was corroborated three of PSTs been at the control group.

\section{Conclusion and Discussion}

This study's main objective is to introduce Kodu Game Lab and digital game based learning to PSTs. In this context, we aimed to make PSTs design their own digital games for science teaching by comprehending Kodu's basic characteristics. Another objective of our study is to come up with PSTs' opinions towards Kodu and digital game based learning. In line with these objectives, we organized the course that been instructed with experimental group based on MAGDAIRE framework. In control group, we didn't use any framework.

We used mixed method in our study. Technical Proficiency of Kodu Concepts Test (TPKC-T) contained thirty items was performed to collect quantitative data and semi-structured interview form consisted of five open-ended questions was used to collect qualitative data. We concentrated on three questions that were prepared within the context of our objectives.

We evaluated data that was collected with TPKC-T to answer the research question 1. Analysis results of TPKC-T data showed that experimental group's post-test mean is significantly higher than control group's post-test mean. According to this finding, it can be said that PSTs' proficiencies towards using Kodu in experimental group are higher than PSTs' in control group. Our courses with 
experimental group were instructed with MAGDAIRE framework and PSTs in this group created their own digital game activities. They worked collaboratively and gave feedback mutually. In control group, we didn't use MAGDAIRE framework. We only introduce Kodu by supporting our courses with Microsoft PowerPoint presentations. PSTs in control group didn't develop digital games and they didn't do group studies such as experimental group. In accordance with these instructions, in reply to question 1 we can determine that it is possible to improve PSTs' Kodu Game Lab proficiency in designing digital game activities by using MAGDAIRE framework for science teaching. Our result is in accordance with the literature. For example, [45] reported that MAGDAIRE developed the PSTs' technology competency levels towards using Adobe Flash.

For answering research question 2, we analyzed interview questions and evaluated PSTs' opinions. PSTs in experimental group though that a course based on digital game based learning with designed software such as Kodu contribute a lot to middle school students. In general, they stated that it is possible to develop students' imagination, their proficiencies in the use of computers and their mental process skills by using digital games. According to them, learning process will be funny with a classroom environment integrated digital game based learning and thus students will like learning science, science courses and their teachers. By means of the influence arising from learning with fun, students will attend to course more actively and in this direction permanent learning will be actualized. Some of them determined that when students work collaboratively, they will socialize. Our participants referred to the importance of collaborative work and they indicated that it will offer the students with an opportunity towards brainstorming. Also when the students work with their own groups, some of our PSTs believed that there will be positive competition among the groups and designing games will be promoted. Allied with these advantages, majority of our PSTs suggested that easy and effective learning for students will be ensured. PSTs in control group made similar statements to us, but number of them is less than PSTs in experimental group. In addition to this, PSTs in control group didn't speak about developing mental process skills, positive competition and permanent learning. Two participants in this group also didn't have any positive opinions towards Kodu and digital game based learning. PSTs in control group especially concentrated upon lack of course time and they emphasized that preliminaries been required by the teacher are time consuming and hard. They also notified that limitations of the software caused problems. Few PSTs in experimental group (e.g. lack of course time: 1 PST) make similar statements and none of them mentioned a problem towards teacher preparation. On the contrary, three PSTs in experimental group stated that all their opinions are positive and there aren't any disadvantages of digital game based learning and Kodu. Based upon analysis of PSTs' answers, it can be reported that PSTs in experimental group have more positive opinions towards Kodu and digital game based learning than PSTs' in control group.

When we viewed our participants' opinions towards availability of Kodu, all PSTs in experimental group talked about its easy installation. Most of them expressed that it is simple to find the software online and it is a real advantage to download Kodu' setup file for free. Half of PSTs in experimental group besides were pleased with finding great numbers of examples towards digital games and worlds on the web. PSTs in control group gave similar answers, but their numbers were less than PSTs in experimental group. In contrast with experimental group, no one from control group mentioned finding these examples. When PSTs opinions towards usage of Kodu are investigated, it is seen that all PSTs in experimental group highlighted program run been user-friendly. They particularly determined that coding and adding characters to their worlds with Kodu is easy since these operations can be done with single click of mouse. They also told us about convenience of creating world and adjusting digital games' difficulty level. All similar replies were given by PSTs in control group. When we contrast experimental group with control group, it is seen that numbers of PSTs in experimental group are more than PSTs' in control group. These findings showed that PSTs in experimental group have more positive opinions towards Kodu than PSTs' in control group. Indeed the findings support above mentioned results.

We used interview question 4 to examine research question 3. All participants from experimental group and three participants from control group reported that they will use digital game based learning and Kodu in their future career. While they were explaining their opinions, they highlighted that classroom environment and learning process will absolutely be enriched with integrating digital games into the classrooms. Three participants from control group's opinions about using digital games in their future classrooms were adverse and according to them, it is not possible to teach science to students with digital games.

Based upon our findings, we can suggest that it is possible to develop PSTs' proficiency in designing digital game and positive opinions towards digital games with MAGDAIRE. This study can help the teachers and faculty to use technology in their classrooms and introduce new technological tools or materials to their students. Researchers determined that teachers are still reluctant to integrate digital games into their courses [22] and they think that it is difficult to use digital games in the classroom [70]. This issue has been investigated especially in recent years. For example, [27] examined the change of PSTs' perceptions with respect to the use of digital mini games to assist middle school level social studies learning and this study's results showed that when teachers played games and had a chance seen the potential for student learning, integrating the game to the course and effective use of the game could be developed. Also [71] emphasized that PSTs who participate 
in technology integration activities in methods courses tend to have more positive attitudes about integrating technology into the classroom. Current study's results are similar with these findings. In our study, participants indicated that when they learned designing games and played the games, their negative feelings about using games in classroom started to change. PSTs started to show a positive tendency to gaming in the classrooms in time. We think that one of the reasons that causes to negative feelings' stems from their inadequate experiences; because PSTs stated that they and their instructors use common strategies for technology integration such as presentations, and videos in the classroom. PSTs also emphasized that because of gaining similar experiences towards technology integration, they are unfamiliar with new techniques been used to integrate technology into the classroom. Several studies stated that prior knowledge and experience about designing activities based on technology are important factors for using technology effectively. For example, [72] revealed that lack of knowledge, skills, and training; and lack of technical support are some of the main barriers to technology use. It can be suggested that introducing Kodu with MAGDAIRE can be one of the solutions for the barriers.

\section{REFERENCES}

[1] Dolenc, K., Aberšek, B. (2015). TECH8 intelligent and adaptive e-learning system: Integration into Technology and Science classrooms in lower secondary schools. Computers \& Education, 82, 354-365.

[2] Ashrafzadeh, A., Sayadian, S. (2015). University instructors' concerns and perceptions of technology integration. Computers in Human Behavior,49, 62-73.

[3] Rehmat, A. P., Bailey, J. M. (2014). Technology Integration in a Science Classroom: Preservice Teachers' Perceptions. Journal of Science Education and Technology,23(6), 744-755.

[4] Cradler, J., McNabb, M., Freeman, M., Burchett, R. (2002). How does technology influence student learning? Learning and Leading with Technology, 29(8), 46-49.

[5] Sivin-Kachala, J., Bialo, E. R. (2000). 2000 research report on the effectiveness of technology in schools. Washington, DC: Software and Information Industry Association.

[6] Peck, K. L. Dorricott, D. (1994). Why use technology?. Educational Leadership,51, 11-11.

[7] Kulik, J. A., Bangert, R. L., Williams, G. W. (1983). Effects of computer-based teaching on secondary school students. Journal of Educational psychology,75(1), 19.

[8] Kiili, K. (2005). Digital game-based learning: Towards an experiential gaming model. The Internet and higher education, $8(1), 13-24$.

[9] Han, I., Eom, M., Shin, W. S. (2013). Multimedia case-based learning to enhance pre-service teachers' knowledge integration for teaching with technologies. Teaching and Teacher Education,34, 122-129.

[10] Cai, Y., Lu, B., Fan, Z., Indhumathi, C., Lim, K. T., Chan, C. W., Li, L. (2006). Bio-edutainment: Learning life science through X gaming. Computers \& Graphics,30(1), 3-9.

[11] Bisson, C., Luckner, J. (1996). Fun in Learning: The Pedagogical Role of Fun in Adventure Education Perspectives. Journal of Experiential Education,19(2), 108.

[12] Mitchell, A., Savill-Smith, C. (2004). The use of computer and video games for learning: A review of the literature.

[13] Prensky, M. (2001). Fun, play and games: What makes games engaging? Digital game-based learning, 5, 1-05.

[14] De Grove, F., Bourgonjon, J., Van Looy, J. (2012). Digital games in the classroom? A contextual approach to teachers' adoption intention of digital games in formal education. Computers in Human behavior,28(6), 2023-2033.

[15] Rosas, R., Nussbaum, M., Cumsille, P., Marianov, V., Correa, M., Flores, P., Rodriguez, P. (2003). Beyond Nintendo: design and assessment of educational video games for first and second grade students. Computers \& Education,40(1), 71-94.

[16] Van Eck, R. (2006). Digital game-based learning: It's not just the digital natives who are restless. EDUCAUSE review,41(2), 16.

[17] Piaget, J. (1962). Plays, dreams, and imitation in childhood. New York: Norton.

[18] Amory, A., Naicker, K., Vincent, J., Adams, C. (1999). The use of computer games as an educational tool: identification of appropriate game types and game elements. British Journal of Educational Technology,30(4), 311-321.

[19] Piaget, J., Campell, R. L. (2014).Studies in reflecting abstraction. Psychology Press.

[20] Spires, H. A. (2015). Digital Game-Based Learning. Journal of Adolescent \& Adult Literacy,59(2), 125-130.

[21] Granic, I., Lobel, A., Engels, R. C. (2014). The benefits of playing video games. American Psychologist,69(1), 66.

[22] Wouters, P., Van Nimwegen, C., Van Oostendorp, H., Van Der Spek, E. D. (2013). A meta-analysis of the cognitive and motivational effects of serious games. Journal of Educational Psychology,105(2), 249.

[23] Rieber, L. P. (1996). Seriously considering play: Designing interactive learning environments based on the blending of microworlds, simulations, and games. Educational technology research and development,44(2), 43-58.

[24] Vogel, J. J., Vogel, D. S., Cannon-Bowers, J., Bowers, C. A., Muse, K., Wright, M. (2006). Computer gaming and interactive simulations for learning: A meta-analysis. Journal of Educational Computing Research,34(3), 229-243.

[25] Lepper, M. R., Cordova, D. I. (1992). A desire to be taught: Instructional consequences of intrinsic motivation. Motivation and emotion,16(3), 187-208.

[26] Alaswad, Z., Nadolny, L. (2015). Designing for Game-Based Learning: The Effective Integration of Technology to Support Learning. Journal of Educational Technology Systems,43(4), 389-402. 
[27] Ray, B., Coulter, G. A. (2010). Perceptions of the value of digital mini-games: Implications for middle school classrooms. Journal of Computing in Teacher Education,26(3), 92-100.

[28] Paraskeva, F., Bouta, H., Papagianni, A. (2008). Individual characteristics and computer self-efficacy in secondary education teachers to integrate technology in educational practice. Computers \& Education,50(3), 1084-1091.

[29] Martens, R., Gulikers, J., Bastiaens, T. (2004). The impact of intrinsic motivation on e-learning in authentic computer tasks. Journal of Computer Assisted Learning,20(5), 368-376.

[30] Garris, R., Ahlers, R., Driskell, J. E. (2002). Games, motivation, and learning: A research and practice model. Simulation \& gaming,33(4), 441-467.

[31] Gee, J. P. (2005). Learning by design: Good video games as learning machines. E-Learning and Digital Media,2(1), 5-16.

[32] Thomas, P., Macredie, R. (1994). Games and the design of human-computer interfaces. Programmed Learning and Educational Technology,31(2), 134-142.

[33] Kirriemuir, J. (2002). The relevance of video games and gaming consoles to the higher and further education learning experience. Techwatch report TSW,2.

[34] De Freitas, S. (2008). Emerging trends in serious games and virtual worlds. Emerging technologies for Learning,3.

[35] Sitzmann, T. (2011). A meta-analytic examination of the instructional effectiveness of computer-based simulation games. Personnel psychology, 64(2), 489-528.

[36] Ritchie, D., Dodge, B. (1992). Integrating Technology Usage across the Curriculum through Educational Adventure Games. Technology and Teacher Education Conference, Houston, TX, March 12-15.

[37] Akcaoğlu, M. (2013).Cognitive and motivational impacts of learning game design on middle school children (Doctoral dissertation, Michigan State University).

[38] Akcaoglu, M., Koehler, M. J. (2014). Cognitive outcomes from the Game-Design and Learning (GDL) after-school program. Computers \& Education,75, 72-81.

[39] Gros, B. (2007). Digital games in education: The design of games-based learning environments. Journal of Research on Technology in Education,40(1), 23-38.

[40] Uttal, D. H., Meadow, N. G., Tipton, E., Hand, L. L., Alden, A. R., Warren, C., Newcombe, N. S. (2013). The malleability of spatial skills: a meta-analysis of training studies. Psychological bulletin,139(2), 352.

[41] Feng, J., Spence, I., Pratt, J. (2007). Playing an action video game reduces gender differences in spatial cognition. Psychological science, 18(10), 850-855.

[42] Okagaki, L., Frensch, P. A. (1994). Effects of video game playing on measures of spatial performance: Gender effects in late adolescence. Journal of applied developmental psychology, 15(1), 33-58.

[43] McGee, M. G. (1979). Human spatial abilities: psychometric studies and environmental, genetic, hormonal, and neurological influences. Psychological bulletin,86(5), 889.

[44] Natale, M. J. (2002). The effect of a male-oriented computer gaming culture on careers in the computer industry. ACM SIGCAS Computers and Society,32(2), 24-31.

[45] Chien, Y. T., Chang, C. Y., Yeh, T. K., Chang, K. E. (2012). Engaging pre-service science teachers to act as active designers of technology integration: A MAGDAIRE framework. Teaching and Teacher Education,28(4), 578-588.

[46] Collins, A., Brown, J. S., Newman, S. E. (1989). Cognitive apprenticeship: Teaching the crafts of reading, writing, and mathematics. Knowing, learning, and instruction: Essays in honor of Robert Glaser, 18, 32-42.

[47] Becker, K. (2007). Digital game-based learning once removed: Teaching teachers. British Journal of Educational Technology,38(3), 478-488.

[48] Bingimlas, K. A. (2009). Barriers to the successful integration of ICT in teaching and learning environments: A review of the literature. Eurasia Journal of Mathematics, Science \& Technology Education,5(3), 235-245.

[49] Pan, A. C., Carroll, S. Z. (2002, December). Preservice teachers explore instructional software with children. In The Educational Forum(Vol. 66, No. 4, pp. 371-379). Taylor \& Francis Group.

[50] Cagiltay, K., Cakiroglu, J., Cagiltay, N., Cakiroglu, E. (2001). Öğretimde bilgisayar kullanımına ilişkin öğretmen görüşleri. Hacettepe Üniversitesi Eğitim Fakültesi Dergisi,21(21).

[51] Yuksel, I., Adiguzel, A. (2012). Ogretmenlerin ogretim teknolojileri entegrasyon becerilerinin değerlendirilmesi: Yeni pedagojik yaklasimlar icin nitel bir gereksinim analizi.Journal of Necatibey Egitim Fakültesi Elektronik Fen ve Matematik Egitimi,6(1).

[52] Dağ, F. (2016). Examination of the professional development studies for the development of technological competence of teachers in Turkey in the context of lifelong learning Yaşam boyu öğrenme bağlamında Türkiye'de öğretmenlerin teknolojik yeterliliklerinin geliştirilmesine yönelik mesleki gelişim çalışmalarının incelenmesi. International Journal of Human Sciences, 13(1), 90-111.

[53] Koehler, M. J., Mishra, P., Yahya, K. (2007). Tracing the development of teacher knowledge in a design seminar: Integrating content, pedagogy and technology. Computers \& Education,49(3), 740-762.

[54] Baek, Y. K. (Ed.). (2010).Gaming for Classroom-Based Learning: Digital Role Playing as a Motivator of Study: Digital Role Playing as a Motivator of Study. IGI Global.

[55] Bolkan, J. V. (2010). Playing games and the NETS. In Hirumi, A. (Ed.), Playing games in school: Video games and simulations for primary and secondary education (pp. 33-56). Eugene, OR: International Society for Technology in Education.

[56] Creswell, J. W. (2003). Research design: Qualitative, quantitative, and mixed methods approaches (2nd ed.). Thousand Oaks, CA: Sage.

[57] Davies, P. (2000). Contributions from qualitative research. What works, 291-316.

[58] Onwuegbuzie, A. J., Leech, N. L. (2004). Enhancing the interpretation of significant findings: The role of mixed methods research. The Qualitative Report,9(4), 770-792. 
[59] CoHE. (2016). Online available from http://www.yok.gov.tr/ 05.02 .2016

[60] Randel, J. M., Morris, B. A., Wetzel, C. D., Whitehill, B. V. (1992). The effectiveness of games for educational purposes: A review of recent research. Simulation \& gaming,23(3), 261-276.

[61] Microsoft Research, Kodu Project. Online available from http://research.microsoft.com/enus/projects/kodu/ 23.07.2016

[62] MacLaurin, M. B. (2011). The Design of Kodu: A Tiny Visual Programming Language for Children on the Xbox 360. ACM SIGPLAN Notices, 46(1).

[63] Touretzky, D. S. (2014). Teaching Kodu with Physical Manipulatives. ACM Inroads, Vol. 5 Issue 4, December, 44-51, ACM New York, NY, USA doi: $10.1145 / 2684721.2684732$

[64] Newell, A., Simon, H. A. (1972). Human problem solving (Vol. 104, No. 9). Englewood Cliffs, NJ: Prentice-Hall.

[65] Someren, M. V., Barnard, Y. F., Sandberg, J. A. (1994). The think aloud method: a practical approach to modelling cognitive processes. Academic Press.

[66] Kalaycı, S. (2010). SPSS Uygulamali Cok Değiskenli Istatistik Teknikleri (Vol. 5). Asil Yayin Dagitim.

[67] Noor, K. B. M. (2008). Case study: A strategic research methodology. American journal of applied sciences,5(11), 1602-1604.

\footnotetext{
i This study is formed from first author's doctoral dissertation been prepared with advisor of second author

Qualitative part of the study was presented at International Teacher Education Conference, Russia, 2015 and quantitative part of the study was presented at International Teacher Education Conference, Dubai, 2016.
}

[68] Büyüköztürk, Ş. (2012). Sosyal bilimler için veri analizi el kitab1.

[69] Cohen, J. (1988). Statistical power analysis for the behavioral sciences (2nd ed.). Hillsdale, NJ: Erlbaum.

[70] Baek, Y. K. (2008). What hinders teachers in using computer and video games in the classroom? Exploring factors inhibiting the uptake of computer and video games. CyberPsychology \& Behavior, 11(6), 665-671.

[71] Polly, D., Mims, C., Shepherd, C. E., Inan, F. (2010). Evidence of impact: Transforming teacher education with preparing tomorrow's teachers to teach with technology (PT3) grants. Teaching and Teacher Education,26(4), 863-870.

[72] Tearle, P., Golder, G. (2008). The use of ICT in the teaching and learning of physical education in compulsory education: how do we prepare the workforce of the future?. European Journal of Teacher Education,31(1), 55-72.

[73] Tømte, C., Enochsson, A. B., Buskqvist, U., \& Kårstein, A. (2015). Educating online student teachers to master professional digital competence: the TPACK-framework goes online. Computers \& Education, 84, 26-35.

[74] Brun, M., \& Hinostroza, J. E. (2014). Learning to become a teacher in the 21st century: ICT integration in Initial Teacher Education in Chile. Educational Technology \& Society, 17, 222-238. 